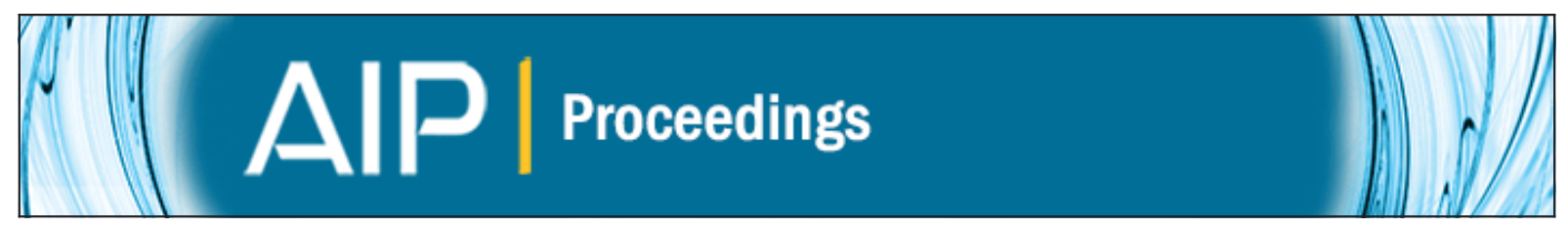

\title{
Preface: Nuclear Weapon Issues in the 21st Century
}

Pierce Corden, David Hafemeister, and Peter Zimmerman

Citation: AIP Conference Proceedings 1596, 1 (2014); doi: 10.1063/1.4876452

View online: http://dx.doi.org/10.1063/1.4876452

View Table of Contents: http://scitation.aip.org/content/aip/proceeding/aipcp/1596?ver=pdfcov

Published by the AIP Publishing

Articles you may be interested in

COMPUTATIONAL ELECTRONICS AND 21ST CENTURY EDUCATION

AIP Conf. Proc. 1239, 3 (2010); 10.1063/1.3459784

The Race for 21st Century Auto Fuels

AIP Conf. Proc. 1044, 235 (2008); 10.1063/1.2993723

Science Education for the 21st Century; A Scientific Approach to Science Education

AIP Conf. Proc. 869, 19 (2006); 10.1063/1.2400629

Streamlined payload processing in the 21st century

AIP Conf. Proc. 552, 189 (2001); 10.1063/1.1357924

Advancing payload processing into the 21st century

AIP Conf. Proc. 504, 136 (2000); 10.1063/1.1302470 


\section{PREFACE}

\section{Nuclear Weapon Issues in the $21^{\text {st }}$ Century}

The global regime for nuclear nonproliferation has been under duress since nuclear weapons were first developed and used in World War II, as seen by the efforts of many nations to acquire nuclear weapons. The twotiered Nuclear Non-Proliferation Treaty (NPT) commits the five nuclear-weapon parties (the permanent members of the UN Security Council: US, UK, Russia, China and France - the P5) not to assist any state in acquiring nuclear weapons, while non-nuclear-weapon parties commit not to acquire nuclear weapons and to implement IAEA safeguards to prevent "diversion of nuclear energy for peaceful uses to nuclear weapons...." India, Pakistan, Israel and North Korea are not NPT parties. This requires dealing in parallel with the capabilities of these four non-NPT states, the P5 states and the 185 non-nuclear NPT parties.

If Iran were to build the bomb, in violation of its NPT obligations, how will NPT non-nuclear-weapon states, such as Saudi Arabia and Egypt, react? If the US, China, or Russia, were to resume nuclear testing, would this lead to testing by others, and to new deployments of nuclear weapons? The NPT regime extends beyond the treaty in numerous ways to help counter those and other risks. Tools, such as diplomacy between nations, arms control, economic sanctions, safeguards and protocols of the International Atomic Energy Agency (IAEA), physical security for nuclear materials and weapons, counter-proliferation military strikes, port and border security, limits on production of weapons-useable uranium and plutonium, export controls on sensitive nuclear technology, regional security, missile defense, and the Proliferation Security Initiative - a global effort to stop trafficking in weapons of mass destruction - are all part of the broader region. That interconnected system must be resilient to unpredictable changes. Further nuclear testing or withdrawal of a nation from the NPT would pose serious challenges to the regime.

Figure 1 and the book cover seek to illustrate in a compact way the history of the spread of nuclear weapons since the first nuclear test in 1945. "Horizontal proliferation" refers to additional states obtaining nuclear weapons, while "vertical proliferation" refers to nuclear-weapon-possessing states obtaining more nuclear weapons. This figure shows that the eight states that have tested a nuclear weapon have proceeded, since their first test, in a similar fashion. The reductions in the stockpiles of the US and USSR-Russia are clear; similarly UK and French weapon numbers have declined. For the others the picture is either uncertain, or the numbers are increasing, although at much lower levels than the US and Russian numbers.

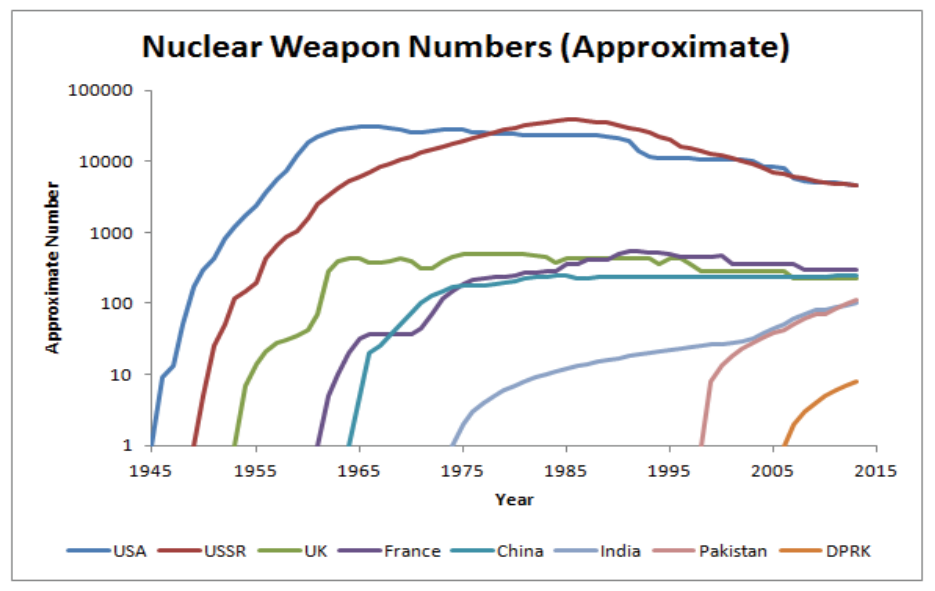

FIGURE 1. Best available information on numbers of nuclear weapons from 1945 to 2012. The logarithm of the number of stockpiled weapons is plotted from left to right, keyed to the date of first nuclear test: US (2013 totals; 4650 stockpile, 2120 operational), Russia (4300 stockpile, 1600 operational), UK (225), France (300), China (250), India (90-110), Pakistan (100-120) and N. Korea (5-10). [Pierce Corden, adapted from data of Hans Kristensen]

Nuclear Weapon Issues in the 21 st Century

AIP Conf. Proc. 1596, 1-4 (2014); doi: 10.1063/1.4876452

(C) 2014 AIP Publishing LLC 978-0-7354-1230-9/\$30.00 
Many now believe that a nuclear weapons confrontation is more likely to happen, but at a lower level of confrontational intensity. We don't know if this is true, but there is some evidence for this conclusion. The global nuclear nonproliferation regime is challenged today, as it has been over the past several decades: It has had to deal with events in India, Iran, Iraq, Israel, Libya, North Korea, Pakistan, South Africa, and Syria. Since the American Physical Society's Forum on Physics and Society had not offered a short course on nuclear weapons since 1988, it seemed clear that we should examine issues they pose once again. This $4^{\text {th }}$ short course followed the following three previous conferences on nuclear weapons offered by the Forum on Physics and Society:

Short Course on the ARMS RACE, San Francisco Hilton Hotel (El Corale, San Luis Obispo, 1982, 179 p.)

Physics, Technology and the Nuclear Arms Race, Baltimore Convention Center (AIPCP 104, 1983, 372p.)

Nuclear Arms Race Technologies in the 1990s, George Washington University (AIPCP 178, 1988, 476 p.)

The $4^{\text {th }}$ short course was held on November 2 to 3, 2013 at the Elliott School of International Affairs of The George Washington University in Washington, DC. It was cosponsored by GWU's Elliot School and the American Physical Society's Forum on Physics and Society. It was organized by Pierce Corden (American Association for the Advancement of Science), David Hafemeister (emeritus, California Poly University) and Peter Zimmerman (emeritus, Kings College London). The November 2013 event covered nuclear weapon issues in five sessions. The power point presentations can be downloaded from the GWU Elliott School at http://elliott.gwu.edu/nuclearweapon-issues-21st-century. The April 2014 issue of Physics Today contains an article on some of the issues discussed. ${ }^{1}$ The short course examined many of the following issues: this volume adds a number of supplementary articles.

Strategic Weapons and Arms Control: Present US policy, an historical discussion on nuclear issues, monitoring START treaties, monitoring nuclear warheads and materials, modernizing the U.S. nuclear arsenal, future nuclear weapon policies, Gorbachev's arms-control advisors, adventures in nuclear diplomacy, environmental consequences of nuclear war, working towards a world without nuclear weapons, and a primer on nuclear exchange models.

Comprehensive Nuclear-Test-Ban Treaty: Fundamentals of the CTBT, the 2012 report of the National Academy of Sciences, seismic monitoring, radioxenon and radionuclide monitoring, CTBT on-site inspections, stockpile stewardship. Proliferation of nuclear weapons is inter-connected with the global ban on nuclear testing on technical and global governance grounds. ${ }^{1}$

Ballistic Missile Defense: National Academy of Sciences study on theater defenses against incoming ballistic missiles, reducing some of the BMD programs, testing the performance of BMD systems, a history of the Soviet view of the Strategic Defense Initiative.

Nuclear Proliferation: The evolution of the non-proliferation regime, the nuclear programs in North Korean, Iran, India and Pakistan, monitoring centrifuges and the blend down of high enriched uranium, laser and centrifuge enrichment systems, monitoring a fissile material cut-off treaty, nuclear forensics.

Mass-Casualty Terrorism, Review and the Future: Science and technology for homeland security, bio-weapons, terrorism and nuclear detection, scanning of vehicles for nuclear materials, workshop review and the future.

\section{Iran and P5-plus-1 Nuclear Agreement}

Three weeks after this conference, the Joint Plan of Action between Iran and the P5 and Germany (P5-plus-1) became public. The Iranian situation was discussed in the presentations of David Albright, (Institute for Science in International Security) Olli Heinonen (former director of IAEA Safeguards, Harvard) and Larry Satkowiak (Oak

1 P. Corden and D. H" femeister, "Nuclear proliferation and testing: A tale of two treaties," Physics Today 67(4), 41-46" (April 2014)." 
Ridge National Laboratroy). See Figure 2 for Iran's centrifuge capacity at Natanz as of November 2013. The Joint Plan of Action went into effect on 20 January 2014. It is hoped that the results of the six-month agreement will lead to a more permanent improved situation.

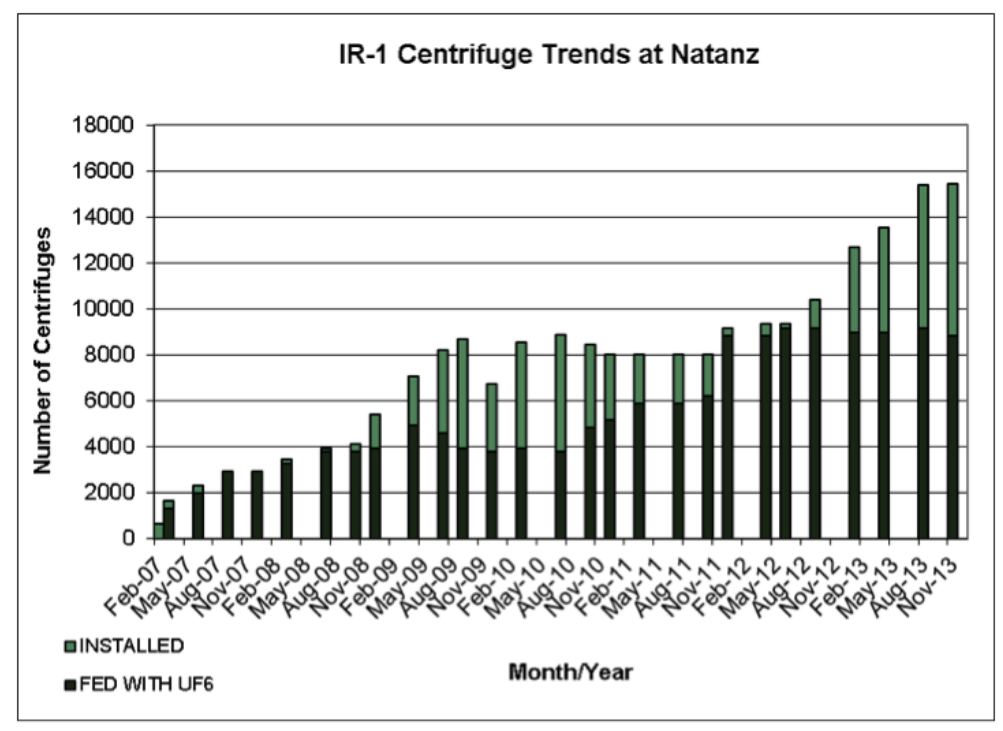

FIGURE 2. The number of IR-1 centrifuges at Natanz, Iran. The inoperable centrifuges during 2009 and 2010 were disabled by cyber events. Natanz has a total of 18,000 centrifuges and Fordow has 2,700. The pause in late 2013 may be related to the negotiations between Iran and the P5-plus-1. [Figure from David Albright]

The Joint Plan of Action places constraints on Iran's nuclear program, while lowering economic sanctions on Iran by $\$ 7$ billion over 6 months, which is reversible if it fails. The actions listed below are being monitored by the IAEA. ${ }^{2}$ It doubles the initial breakout time of 1 to 2 months to obtain sufficient HEU for one nuclear weapon. It is hoped that a final agreement can increase the breakout time. This can be done with a ban on possession of $20 \%$ enriched uranium with a limit of 6000 IR-1 centrifuges (6 months) or a limit of 3000 IR-1 centrifuges (12 months).

1. Halt uranium enrichment above 5\%, preventing near-20\% HEU production;

2. Neutralize near- $20 \%$ enriched HEU stock of $190 \mathrm{~kg}$ by oxidation or dilution;

3. Halt installation of additional centrifuges at Natanz, Fordow and elsewhere;

4. Cap production of $3.5 \%$ enriched LEU by non-operation of 12 cascades;

5. Freeze advances at Arak heavy water reactor, with monthly inspections;

6. Daily inspections at Natanz and Fordow with managed access;

7. Access to centrifuge assembly and production facilities;

8. Earlier notification and information about new nuclear facilities; and

9. Access to uranium mines and mills.

The participants of the short course on nuclear weapons issues appreciate the kind and gracious hospitality shown by the GWU Elliott School of International Affairs. We are particularly thankful for the help of Associate Dean Doug Shaw and Christina Walrond.
Pierce Corden
David Hafemeister
AAAS, Washington, DC
Cal Poly Univ., San Luis Ob, CA
Peter Zimmerman
Kings College, London

\footnotetext{
2 Department of State, Background briefing on implementation Plan of P5+1 and Iran's First Step Nuclear Agreement, 13 January 2014, www.state.gov/r/pa/prs/ps/2014/01/21957/htm, www.whitehouse.gov, www.isis-online.org. "
} 


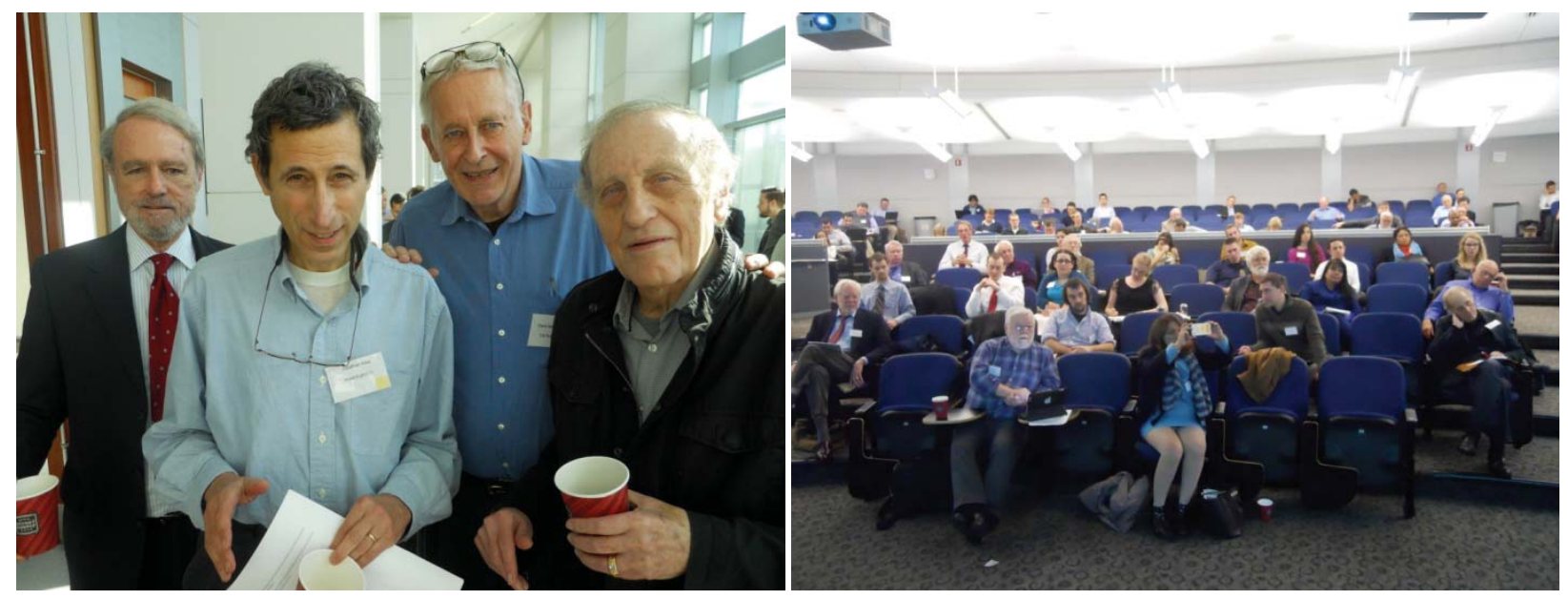

Left to Right: Pierce Corden (co-organizer), Jonathan Katz (Vehicle Scanning), David Hafemeister (co-organizer), Milton Hoenig, and some of the 144 attendees.

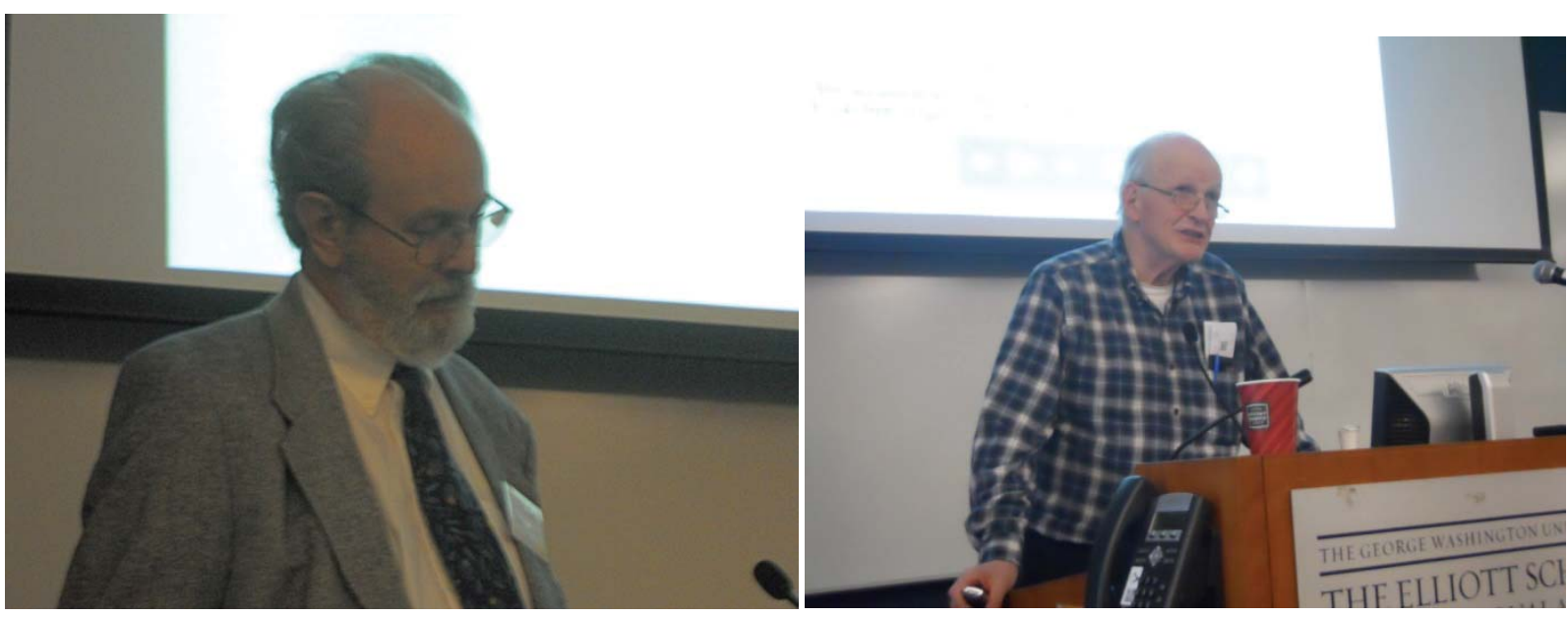

Left to right: Paul Richards (CTBT Seismology) and Frank von Hippel (Fissile Material Cut-off Monitoring)
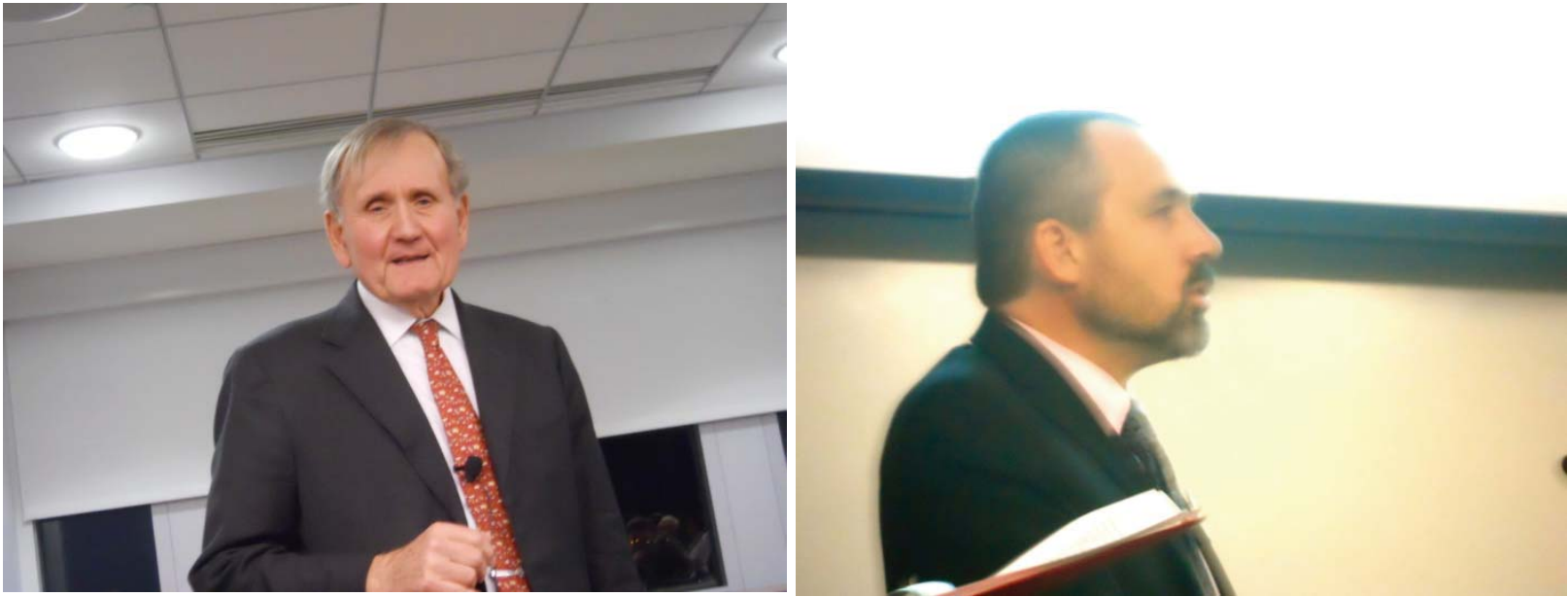

Left to right: Ambassador Thomas Graham (Arms Control Negotiator) and Ted Bowyer (Radio-xenon Monitoring) 